\title{
Polymorphisms in four microRNAs and risk of oral squamous cell cancer: a meta-analysis
}

\author{
Junfeng Zeng ${ }^{1, *}$, Xiaowei Yí, ${ }^{2}$, , Hao Liu ${ }^{1}$, Yi Yang ${ }^{1}$, Yuchen Duan ${ }^{1}$ and Hua Chen ${ }^{1}$ \\ ${ }^{1}$ Department of Orthopedics, West China Hospital, Sichuan University, Chengdu, 610041, China \\ ${ }^{2}$ State Key Laboratory of Oral Diseases, National Clinical Research Center for Oral Diseases, West China Hospital of \\ Stomatology, Sichuan University, Chengdu,610041, China \\ *These authors contributed equally to this work
}

Correspondence to: Hao Liu, email: liuhaosurgery@126.com

Keywords: microRNAs; polymorphism; oral squamous cell cancer (OSCC); cancer biomarkers; meta-analysis

Received: August 23, $2017 \quad$ Accepted: December 05, $2017 \quad$ Published: January 12, 2018

Copyright: Zeng et al. This is an open-access article distributed under the terms of the Creative Commons Attribution License 3.0 (CC BY 3.0), which permits unrestricted use, distribution, and reproduction in any medium, provided the original author and source are credited.

\section{ABSTRACT}

Objectives: Single nucleotide polymorphisms in microRNAs (microRNA-196a2 rs11614913, microRNA-146a rs2910164, microRNA-149 rs2292832 and microRNA-499 rs3746444) have been inconsistently associated with risk for oral squamous cell cancer (OSCC). This meta-analysis aimed to assess the correlation between microRNA polymorphisms and susceptibility to OSCC.

Materials and Methods: Free words were used to search for the relevant studies without language limitations in electronic databases including PubMed, Embase, Web of Science and SCOPUS through June 15, 2017. Odds ratios (ORs) were calculated to investigate the effects of microRNA polymorphisms on oral cancer risk.

Results: Eleven studies were included. Analysis under the recessive model of microRNA-146a (CC vs GG+CG) showed significant differences (ORs = 0.874, $P=$ 0.041 ). The $G$ allele and the GG genotype of microRNA-499 were associated with OSCC risk (ORs $>1, P<0.05$ ). MicroRNA-196a2 rs11614913 and microRNA-149 polymorphisms appeared to have no relationship with OSCC risk $(P>0.05)$. In the sensitivity analysis, there was a significant association between the TT genotype of microRNA-196a 2 and OSCC risk (TT vs TC + CC, ORs $<1, P<0.05$ ).

Conclusions: There may be no significant relationship between microRNA-149 polymorphisms and OSCC risk, and the CC genotype of microRNA-146a may have protective effects against oral cancer. However, the G allele and the GG genotype of microRNA-499 may increase OSCC risk.

\section{INTRODUCTION}

The Incidence of oral cancer cases has been steadily increasing, due to population growth and changes in age structure [1]. Globally, the incidence of oral cancer has been estimated to increase by $62 \%$ through 2035 [2]. Oral squamous cell cancer (OSCC) is the most common malignancy of oral cancers, accounting for approximately $90 \%$ of all oral cancers [3]. Numerous studies have aimed to explore and uncover risk factors for developing OSCC. Genetic variation was highlighted in previous studies as a potential risk factor $[4,5]$.
MicroRNAs (miRNAs), which are endogenous, small non-coding RNAs, are critical to the regulation of physiology and disease progression, including oral cancers [6]. MiRNAs can induce messenger RNA (mRNA) cleavage or repress translation by targeting the 3 '-untranslated region (UTR) of mRNA [7]. Consequently, dysregulated protein expression associated with single nucleotide polymorphisms (SNPs) in miRNAs can alter OSCC etiology.

MiRNAs exhibit remarkable tissue specificity [8], and miRNA biomarkers for OSCC may differ from those of other cancers. Several aberrantly expressed miRNA 
variants have been observed in OSCC patients, including microRNA-196a2 [9-16], microRNA-146a [9, 10, 12, 14, $17,18]$, microRNA-149 [10, 12, 15] and microRNA-499 [9, 10, 19], among others. However, no consensus has been reached regarding whether and to what extent miRNAs could influence susceptibility to OSCC.

Abnormal microRNA polymorphisms in OSCC warrant more research to provide a basis for diagnosis, therapy and screening for the high-risk OSCC population. Advances in our efforts to detect the role of miRNAs in genetic susceptibility to OSCC may further elucidate their role in regulating OSCC risk and may identify certain miRNAs as oncogenic biomarkers. Therefore, the purpose of this study was to review the literature for evidence of correlations between certain microRNA polymorphisms and the risk of oral squamous cell cancer.

\section{RESULTS}

\section{Literature search and study inclusion}

The initial electronic database searches of PubMed, Embase, Web of science and SCOPUS yielded $967,18,160$, and 110 potentially studies, respectively. After reading the titles and abstracts of those studies, 20 articles were chosen for full-text reading, and their references were screened. Finally, 11 eligible studies on SNPs in miRNAs were included after the unqualified studies were discarded (Figure 1). Following that assessment, a data extraction form was constructed for the characteristics of the chosen studies (Table 1), and the data from the 11 included studies were extracted and synthesized. Of the 11 studies, 3 studies were given a score of 5 and recognized as high risk. In contrast, 3 high-quality trials were given a score of 7 . The remaining 5 studies had a moderate risk of bias (Table 2).

\section{Association between the microRNA-196a2 rs11614913 polymorphism and risk of OSCC (Table 3)}

A total of 8 studies [9-16] on the dominant model and 6 studies $[9-13,15]$ on the other 4 genetic models were involved in this meta-analysis. There was no significant association between the microRNA-196a2 polymorphisms and risk of OSCC under any genetic model tested ( $P>0.05$ for all models). The ORs in all 5 models were close to 1 , which may suggest that the microRNA$196 a 2$ rs 11614913 polymorphism has a very low effect on OSCC risk. However, the sensitivity analysis, which was conducted by eliminating one study at a time $[9,11$, 13], indicated that the TT genotype of microRNA-196a2 rs 11614913 decreased OSCC risk (TT vs $T C+C C, I^{2}<$ $50 \%, O R<1, P<0.05$ ) (Figure 2).

\section{Association between the microRNA-146a rs2910164 polymorphism and risk of OSCC} (Table 3)

A pooled analysis of 6 studies [9, 10, 12, 14, 17, 18] involving 2323 cases and 5059 controls showed no significant changes under any genetic model, except for the recessive model (CC vs $G G+C G, I^{2}=0 \%, O R=0.874,95 \% C I=$ $0.768 \sim 0.994, P=0.041$ ) (Figure 3 ). The genotype allocation of the microRNA-146a rs2910164 polymorphism was found to be in Hardy-Weinberg equilibrium (HWE) in all included comparisons $\left(P_{\mathrm{HWE}}>0.05\right.$ for all models). Heterogeneity was not found in any of the genetic models $\left(\mathrm{I}^{2}=0 \%\right.$ for all). The high level of agreement among the included studies provided powerful evidence that there is a strong negative correlation between the CC genotype of microRNA-146a rs2910164 and OSCC risk.

\section{Association between the microRNA-149 rs2292832 polymorphism and risk of OSCC (Table 3)}

For microRNA-149 rs2292832, 3 studies [10, 12, 15] were eligible, involving 1356 cases and 2410 controls. Although the ORs in all genetic models were greater than 1 , no significant association was observed in any of the 5 genetic models. However, these studies showed apparent heterogeneity $\left(\mathrm{I}^{2} \geq 50 \%\right)$. Therefore, further welldesigned studies investigating the relationship between the microRNA-149 rs2292832 polymorphism and risk of OSCC are warranted.

\section{Association between the microRNA-499 rs3746444 polymorphism and risk of OSCC} (Table 3)

As indicated in Table 3 and Figure 4, a pooled analysis of 3 studies [9, 10, 19] showed a significant association between the microRNA-499 rs3746444 polymorphism and risk for OSCC under the allele model ( $\mathrm{G}$ vs A, $\mathrm{I}^{2}=39.9 \%$, $\mathrm{OR}=1.57,95 \% \mathrm{CI}=1.318 \sim 1.871, P=0.000)$, the additive model (GG vs AA, $\mathrm{I}^{2}=0 \%, \mathrm{OR}=3.430,95 \% \mathrm{CI}$ $=1.914 \sim 6.146, P=0.000$ ), the codominant model (GA vs $\mathrm{AA}, \mathrm{I}^{2}=62.2 \%, \mathrm{OR}=1.407,95 \% \mathrm{CI}=1.142 \sim 1.733, P=$ 0.001 ), the dominant model (GG+GA vs AA, $\mathrm{I}^{2}=36.8 \%$, $\mathrm{OR}=1.484,95 \% \mathrm{CI}=1.253 \sim 1.758, P=0.000)$ and the recessive model $\left(\mathrm{GG}\right.$ vs $\mathrm{GA}+\mathrm{AA}, \mathrm{I}^{2}=0 \%, \mathrm{OR}=3.165$, $95 \% \mathrm{CI}=1.777 \sim 5.637, P<0.00001)$. The high ORs in all genetic models (ORs $>1$ ) indicate that the $\mathrm{G}$ allele and the GG genotype of microRNA-499 rs3746444 increase the risk for oral cancer.

\section{Publication bias and sensitivity analysis}

To confirm the outcome of our analyses, we conducted a sensitivity analysis by sequentially 


\begin{tabular}{|c|c|c|c|c|c|c|c|c|c|c|c|c|c|c|}
\hline \multirow[t]{2}{*}{ Reference } & \multirow[t]{2}{*}{ Country } & \multirow[t]{2}{*}{ Source of control } & \multirow[t]{2}{*}{$\begin{array}{l}\text { Case/ } \\
\text { Control }\end{array}$} & \multicolumn{10}{|c|}{ Genotype distribution } & \multirow{2}{*}{ P for HWE } \\
\hline & & & & \multicolumn{4}{|c|}{ Case } & \multicolumn{6}{|c|}{ Control } & \\
\hline \multicolumn{15}{|c|}{ microRNA-196a2 rs11614913 C > T } \\
\hline & & & & $\mathrm{C}$ & $\mathrm{T}$ & $\mathrm{CC}$ & $\mathrm{TC}$ & TT & $\mathrm{C}$ & $\mathrm{T}$ & $\mathrm{CC}$ & $\mathrm{TC}$ & TT & \\
\hline Zhang E, 2017 & China & Hospital-based & $340 / 340$ & 311 & 369 & 71 & 169 & 100 & 331 & 349 & 88 & 155 & 97 & 0.106 \\
\hline Miao L, 2016 & China & Hospital-based & $462 / 1550$ & 452 & 472 & 112 & 228 & 122 & 1339 & 1761 & 292 & 755 & 503 & 0.796 \\
\hline Sushma PS, 2015 & India & Not mentioned & $100 / 102$ & 54 & 146 & 22 & 10 & 68 & 27 & 177 & 6 & 15 & 81 & 0.00028 \\
\hline Roy R, 2014 & India & Hospital-based & $451 / 448$ & 623 & 279 & 218 & 187 & 46 & 652 & 244 & 242 & 168 & 38 & 0.25 \\
\hline Liu CJ, 2013 & Taiwan & Not mentioned & $315 / 92$ & 275 & 355 & 64 & 147 & 104 & 88 & 96 & 26 & 36 & 30 & 0.04 \\
\hline Chu YH, 2012 & Taiwan & Hospital-based & $470 / 425$ & 391 & 549 & 57 & 277 & 136 & 380 & 470 & 87 & 206 & 132 & 0.68 \\
\hline \multicolumn{15}{|c|}{ microRNA-146a rs2910164 G >C } \\
\hline & & & & G & $\mathrm{C}$ & GG & CG & $\mathrm{CC}$ & $\mathrm{G}$ & $\mathrm{C}$ & GG & CG & $\mathrm{CC}$ & \\
\hline Zhang E, 2017 & China & Hospital-based & $340 / 340$ & 178 & 502 & 27 & 124 & 189 & 152 & 528 & 19 & 114 & 207 & 0.53 \\
\hline Miao L, 2016 & China & Hospital-based & $462 / 1548$ & 536 & 388 & 154 & 228 & 80 & 1767 & 1329 & 497 & 773 & 278 & 0.46 \\
\hline Palmieri A, 2014 & Italy & Population-based & $337 / 1176$ & 515 & 159 & 197 & 121 & 19 & 1730 & 622 & 647 & 436 & 93 & 0.10 \\
\hline Chu YH, 2012 & Taiwan & Hospital-based & $470 / 425$ & 350 & 590 & 54 & 242 & 174 & 304 & 546 & 54 & 196 & 175 & 0.93 \\
\hline Chen CH, 2016 & Taiwan & Hospital-based & $512 / 668$ & 383 & 641 & 71 & 241 & 200 & 499 & 837 & 103 & 293 & 272 & 0.10 \\
\hline \multicolumn{15}{|c|}{ microRNA-149 rs2292832 C > T } \\
\hline & & & & $\mathrm{T}$ & $\mathrm{C}$ & TT & $\mathrm{TC}$ & $\mathrm{CC}$ & $\mathrm{T}$ & $\mathrm{C}$ & TT & $\mathrm{TC}$ & $\mathrm{CC}$ & \\
\hline Miao L, 2016 & China & Hospital-based & $461 / 1548$ & 645 & 277 & 226 & 193 & 42 & 2099 & 997 & 726 & 647 & 175 & 0.092 \\
\hline Sushma PS, 2015 & India & Not mentioned & $100 / 102$ & 34 & 166 & 6 & 22 & 72 & 12 & 192 & 0 & 12 & 90 & 0.52 \\
\hline Chu YH, 2012 & Taiwan & Hospital-based & $470 / 425$ & 778 & 162 & 345 & 88 & 37 & 714 & 136 & 315 & 84 & 26 & 4.84 \\
\hline \multicolumn{15}{|c|}{ microRNA-499 rs3746444 A> G } \\
\hline & & & & G & A & GG & GA & $\mathrm{AA}$ & G & A & GG & GA & $\mathrm{AA}$ & \\
\hline Zhang E, 2017 & China & Hospital-based & $340 / 340$ & 180 & 500 & 31 & 118 & 191 & 135 & 545 & 12 & 111 & 217 & 0.633 \\
\hline Hou YY, 2015 & $\begin{array}{l}\text { China, } \\
\text { Taiwan }\end{array}$ & Hospital-based & $155 / 204$ & 49 & 261 & 5 & 39 & 111 & 53 & 355 & 1 & 51 & 152 & 0.13 \\
\hline Chu YH, 2012 & $\begin{array}{l}\text { China, } \\
\text { Taiwan }\end{array}$ & Hospital-based & $470 / 425$ & 143 & 797 & 12 & 119 & 339 & 72 & 778 & 3 & 66 & 356 & 0.97 \\
\hline
\end{tabular}

HWE: Hardy-Weinberg equilibrium

eliminating one study at a time. The sensitivity analysis revealed that certain studies significantly influenced the correlation between microRNA polymorphism and risk of OSCC. The TT genotype of microRNA-196a2 rs11614913 was found to potentially decrease OSCC risk (TT vs $\left.T C+C C, I^{2}<50 \%, O R<1, P<0.05\right)$ when three studies were excluded [9, 11, 13] (Figure 5). From the illustrated data on microRNA-196a2 in those three studies, the authors confused minor allele frequency (MAF) [9], and the genetic distribution of the controls was not in HWE [11]. For the recessive model of microRNA-146a, three studies $[9,10,17]$ influenced the statistical significance of the correlation between polymorphism and risk of OSCC (Figure 5). We surmise that the small number of studies included in our meta-analysis may contribute to the influence of the aforementioned studies; if more studies had been included, the influence of any one study would be decreased.

We performed Egger's test and Begg's test to determine publication bias $\left(\mathrm{P}_{\text {Egger }}>0.05, \mathrm{P}_{\text {Begg }}>0.05\right)$ using Stata version 14.0 software (StataCorp LP, College
Station, TX, USA). No significant publication bias was observed, except in the case of the additive model of microRNA-499 (Table 3).

\section{DISCUSSION}

Numerous studies have been conducted to investigate whether miRNAs affect susceptibility to OSCC, and the results have been controversial and inconsistent. This is the first meta-analysis conducted to assess the association between selected miRNAs and OSCC risk. Data from 8 and 3 studies indicated that microRNA-196a2 rs11614913 and microRNA-149 rs2292832 polymorphisms, respectively, have no significant effect on OSCC risk. However, the sensitivity analysis suggested that the TT genotype of microRNA196a2 may decrease OSCC risk when one study was excluded. We also found that the GG genotype of microRNA-146a rs2910164 may negatively regulate OSCC risk. The pooled analysis of 3 studies showed that there may be a significant association between the $\mathrm{G}$ allele 
Table 2: NOS scores of included studies

\begin{tabular}{|c|c|c|c|c|c|c|c|c|c|c|c|}
\hline \multirow{2}{*}{$\begin{array}{c}\text { Author } \\
\text { (Ref) }\end{array}$} & \multirow[t]{2}{*}{ Year } & \multirow{2}{*}{$\begin{array}{c}\text { Case } \\
\text { Definition }\end{array}$} & \multicolumn{2}{|c|}{ Control } & \multicolumn{2}{|c|}{ Comparability } & \multicolumn{4}{|c|}{ Exposure } & \multirow[t]{2}{*}{ Score } \\
\hline & & & $\begin{array}{l}\text { Represent } \\
\text { ativeness }\end{array}$ & Selection & Definition & $\begin{array}{l}\text { Important } \\
\text { factors }\end{array}$ & $\begin{array}{l}\text { Other } \\
\text { factors }\end{array}$ & $\begin{array}{l}\text { Ascertain- } \\
\text { ment }\end{array}$ & Method & $\begin{array}{l}\text { Non- } \\
\text { response } \\
\text { rate }\end{array}$ & \\
\hline Zhang E & 2017 & $\star$ & $\star$ & $\dot{s}$ & $\star$ & $\star$ & $\star$ & $\sum\langle$ & $\star$ & $\hbar$ & 6 \\
\hline Miao L & 2016 & $\star$ & $\star$ & $\star$ & $\star$ & $\star$ & $\star$ & $\sum$ & $\star$ & $\sum$ & 7 \\
\hline Sushma PS & 2015 & 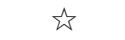 & $\star$ & $\dot{s}$ & $\star$ & $\star$ & $\star$ & $i s$ & $\star$ & $i s$ & 5 \\
\hline Hou, YY & 2015 & $\star$ & $\star$ & $\dot{t}$ & $\star$ & $\star$ & $\star$ & 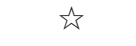 & $\star$ & $\bar{t}$ & 6 \\
\hline Roy, R & 2014 & 功 & $\star$ & 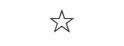 & $\star$ & $\star$ & $\star$ & $i s$ & $\star$ & 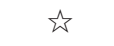 & 5 \\
\hline Liu CJ & 2013 & $\star$ & $\star$ & $\dot{s}$ & $\star$ & $\star$ & $\star$ & 为 & $\star$ & $i s$ & 5 \\
\hline Song X & 2013 & $\star$ & $\star$ & $i$ & $\star$ & $\star$ & $\star$ & 弥 & $\star$ & $\star$ & 7 \\
\hline Chu YH & 2012 & $\hat{\psi}$ & $\star$ & $\dot{s}$ & $\star$ & $\star$ & $\star$ & $\sum$ & $\star$ & $\star$ & 6 \\
\hline Palmieri a & 2014 & $\star$ & $\star$ & $\dot{s}$ & $\star$ & $\star$ & $\star$ & 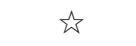 & $\star$ & $i$ & 6 \\
\hline Chen CH & 2016 & $\star$ & $\star$ & 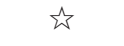 & $\star$ & $\star$ & $\star$ & 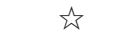 & $\star$ & $\bar{t}$ & 6 \\
\hline $\begin{array}{l}\text { Christensen } \\
\text { BC }\end{array}$ & 2010 & $\star$ & $\star$ & $\star$ & $\star$ & $\star$ & $\star$ & $\hat{s}$ & $\star$ & 柁 & 7 \\
\hline
\end{tabular}

NOS: Newcastle-Ottawa Scale

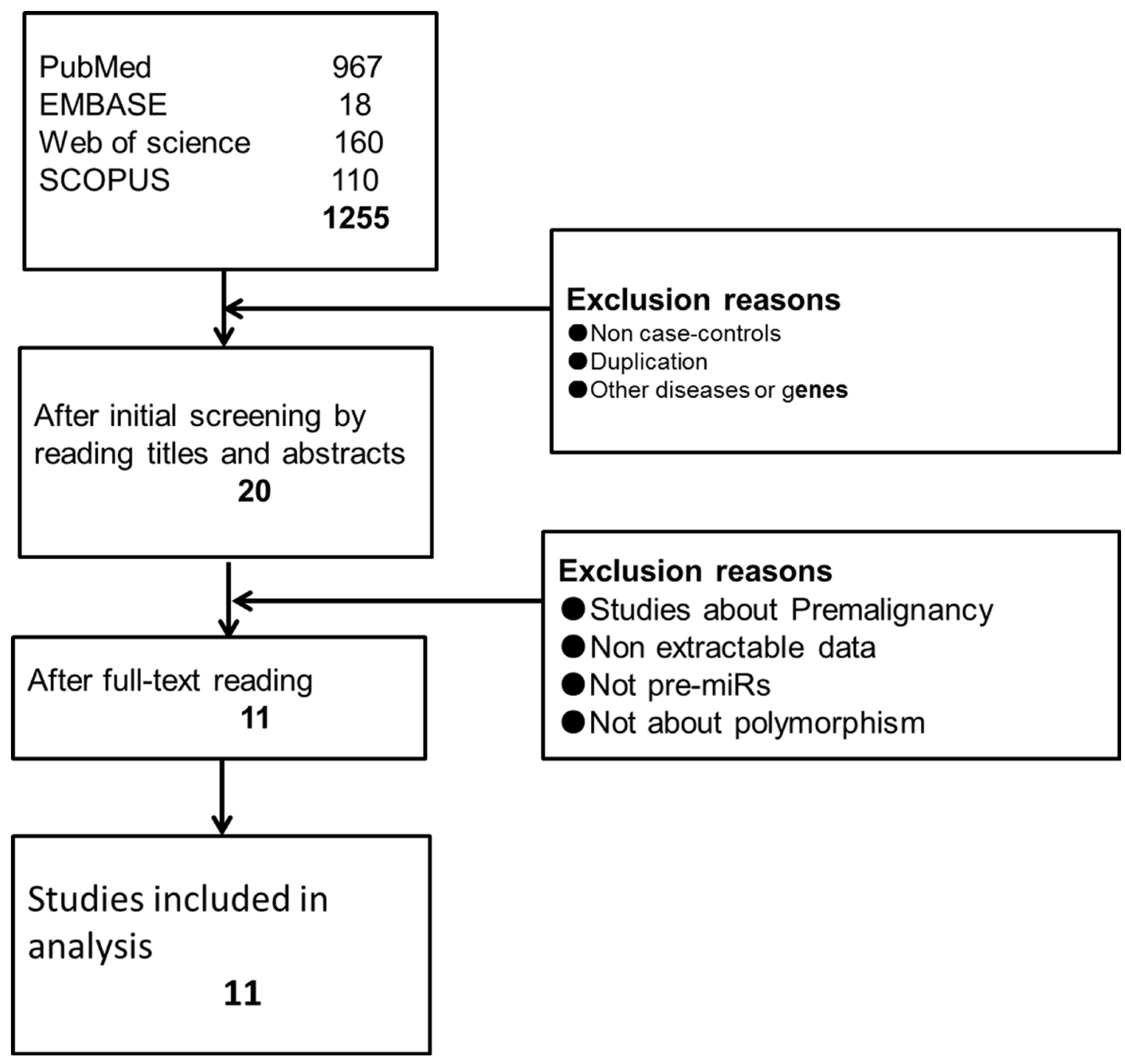

Figure 1: Flow diagram of screening studies. 
Table 3: Summary of tests for association between polymorphisms in four microRNAs and OSCC risk, of publication bias, and of included study number, under all genetic models of four miRNAs

\begin{tabular}{|c|c|c|c|c|c|c|c|}
\hline \multirow[t]{2}{*}{ Comparison } & \multicolumn{3}{|c|}{ Test of association } & \multicolumn{2}{|c|}{ Publication bias } & \multicolumn{2}{|c|}{ Number } \\
\hline & ORs & $95 \%$ CIs & $\boldsymbol{P}$ & PEgger & PBegg & Cases & Controls \\
\hline \multicolumn{8}{|c|}{ microRNA-196a2 rs11614913 C > T } \\
\hline T vs $\mathrm{C}$ & 0.984 & $0.903 \sim 1.073$ & 0.719 & 0.803 & 0.707 & 4276 & 5914 \\
\hline TT vs CC & 0.974 & $0.817 \sim 1.161$ & 0.766 & 0.992 & 1.000 & 952 & 1566 \\
\hline TC vs CC & 1.159 & $0.999 \sim 1.345$ & 0.051 & 0.838 & 0.707 & 1759 & 2076 \\
\hline $\mathrm{TT}+\mathrm{TC}$ vs CC & 1.105 & $0.937 \sim 1.10$ & 0.710 & 0.926 & 0.902 & 2732 & 3847 \\
\hline $\mathrm{TT}$ vs $\mathrm{TC}+\mathrm{CC}$ & 0.877 & $0.763 \sim 1.007$ & 0.063 & 0.696 & 0.707 & 1823 & 2865 \\
\hline \multicolumn{8}{|c|}{ microRNA-146a rs2910164 G >C } \\
\hline G vs $\mathrm{C}$ & 0.946 & $0.877 \sim 1.021$ & 0.153 & 0.259 & 0.452 & 4936 & 10298 \\
\hline GG vs CC & 0.921 & $0.776 \sim 1.092$ & 0.344 & 0.258 & 0.707 & 1386 & 2988 \\
\hline $\mathrm{GC}$ vs $\mathrm{CC}$ & 1.008 & $0.890 \sim 1.141$ & 0.900 & 0.818 & 0.707 & 1785 & 4067 \\
\hline $\mathrm{GG}+\mathrm{GC}$ vs $\mathrm{CC}$ & 1.000 & $0.896 \sim 1.117$ & 0.996 & 0.951 & 0.764 & 2793 & 5484 \\
\hline $\mathrm{GG}$ vs $\mathrm{CC}+\mathrm{GC}$ & 0.874 & $0.768 \sim 0.994$ & 0.041 & 0.100 & 0.221 & 2468 & 5149 \\
\hline \multicolumn{8}{|c|}{ microRNA-149 rs2292832 C > T } \\
\hline T vs $\mathrm{C}$ & 1.098 & $0.963 \sim 1.252$ & 0.161 & 0.494 & 1.000 & 2062 & 4150 \\
\hline TT vs CC & 1.172 & $0.875 \sim 1.569$ & 0.287 & 0.636 & 1.000 & 728 & 1332 \\
\hline $\mathrm{TC}$ vs $\mathrm{CC}$ & 1.195 & $0.896 \sim 1.593$ & 0.225 & 0.850 & 1.000 & 454 & 1034 \\
\hline $\mathrm{TT}+\mathrm{TC}$ vs CC & 1.128 & $0.923 \sim 1.389$ & 0.238 & 0.480 & 0.734 & 1356 & 2410 \\
\hline $\mathrm{TT}$ vs $\mathrm{TC}+\mathrm{CC}$ & 1.070 & $0.903 \sim 1.267$ & 0.437 & 0.396 & 1.000 & 1031 & 2075 \\
\hline \multicolumn{8}{|c|}{ microRNA-499 rs3746444 A > G } \\
\hline G vs A & 1.570 & $1.318 \sim 1.871$ & 0.000 & 0.802 & 1.000 & 1930 & 1938 \\
\hline GG vs AA & 3.430 & $1.914 \sim 6.146$ & 0.000 & 0.023 & 0.296 & 689 & 741 \\
\hline GA vs AA & 1.407 & $1.142 \sim 1.733$ & 0.001 & 0.668 & 1.000 & 917 & 953 \\
\hline $\mathrm{GG}+\mathrm{GA}$ vs $\mathrm{AA}$ & 1.484 & $1.253 \sim 1.758$ & 0.000 & 0.621 & 0.734 & 1290 & 1304 \\
\hline GG vs GA + AA & 3.165 & $1.777 \sim 5.637$ & 0.000 & 0.061 & 0.296 & 965 & 969 \\
\hline
\end{tabular}

PEgger: $P$ value for Egger's test. PBegg: $P$ value for Begg's test. No significant publication bias is observed if PEgger $>$ 0.05 and $\mathrm{PBegg}>0.05$.

and the GG genotype of the microRNA-499 rs3746444 polymorphism and risk for OSCC.

OSCC is one of the most challenging and aggressive cancers, and it remains difficult to detect. MiRNAs, which are regulators of biological processes, regulate the pathogenesis of oral cancer and are thought to be potential biomarkers in cancer diagnosis, based upon their aberrant expression and single nucleotide polymorphisms [20]. Novel therapeutic techniques can also target miRNAs to treat OSCC. In a systematic review, the 4 miRNAs discussed in this report (microRNA-196a2 rs11614913, microRNA-146a rs2910164, microRNA-149 rs2292832 and microRNA-499 rs3746444) were found to potentially contribute to the genesis, progression and prognosis of OSCC [21]. As a result, more research on these promising candidate biomarkers is warranted to confirm the correlation between their single nucleotide polymorphisms and cancer risk.

The genetic variant of miR-196a2, a C to T nucleotide substitution, has been well studied and is thought be related to OSCC risk. Located in a region of the homeobox (HOX) genes, miR-196a plays an important role in regulating HOX expression and function [22]. By targeting important regulatory molecules, including HOX8 [23], miR-196 affects oncogenesis [24]. However, miR-196a either promotes or inhibits tumorigenesis, depending on the type of cancer. In breast cancer cells, pre-miR-196a2-T is converted less frequently than pre-mir-196a2-C into the mature miR-196a [25]. That finding is in agreement with our findings that the TT genotype of microRNA-196a2 may inhibit the genesis of OSCC. Furthermore, our pooled analysis was in agreement with a previous meta-analysis, 
Database

\begin{tabular}{|c|c|}
\hline Database & Search strategy \\
\hline PubMed & $\begin{array}{l}((((((\text { miRNA genes }) \text { OR microRNA) OR miRNA })) \text { AND }((((()((\text { OSCC }) \text { OR oral squamous cell } \\
\text { carcinoma) OR mouth neoplasm) OR oral cancer }) \text { OR oral carcinoma }) \text { OR oral tumor }))))) \text { AND } \\
(((((((((((((\text { Variants) OR SNP) OR polymorphisms) OR mutation) OR allele) OR genotype) } \\
\text { OR Susceptibility) OR Variant) OR SNPs) OR polymorphism) OR mutations }) \text { OR alleles }) \text { OR } \\
\text { genotypes) OR Susceptibilities })\end{array}$ \\
\hline Embase & $\begin{array}{l}\text { (exp microRNA AND (exp genetic polymorphism/ or exp single nucleotide polymorphism/ or } \\
\text { exp DNA polymorphism) AND exp mouth squamous cell carcinoma)) }\end{array}$ \\
\hline Web of science & $\begin{array}{l}\text { TOPIC: (miRNA) OR TOPIC: (microRNA) OR TOPIC: (microRNAs) OR TOPIC: (miRNA) } \\
\text { AND TOPIC: (OSCC) OR TOPIC: (oral squamous cell carcinoma) OR TOPIC: (mouth } \\
\text { neoplasm) OR TOPIC: (oral cancer) OR TOPIC: (oral carcinoma) OR TOPIC: (oral tumor) } \\
\text { AND TOPIC: (Variants) OR TOPIC: (SNP) OR TOPIC: (polymorphism) OR TOPIC: } \\
\text { (mutation) OR TOPIC: (allele) OR TOPIC: (genotype) }\end{array}$ \\
\hline SCOPUS & $\begin{array}{l}\text { ((TITLE-ABS-KEY (mirna) OR TITLE-ABS-KEY (microrna) OR TITLE-ABS-KEY } \\
\text { (micrornas) OR TITLE-ABS-KEY (mirnas))) AND ((TITLE-ABS-KEY (oscc) OR TITLE- } \\
\text { ABS-KEY (oral AND squamous AND cell AND carcinoma) OR TITLE-ABS-KEY } \\
\text { (mouth AND neoplasm) OR TITLE-ABS-KEY (oral AND cancer) OR TITLE-ABS-KEY } \\
\text { (oral AND carcinoma) OR TITLE-ABS-KEY (oral AND tumor))) AND ((TITLE-ABS- } \\
\text { KEY (variants) OR TITLE-ABS-KEY (snp) OR TITLE-ABS-KEY (polymorphisms) } \\
\text { OR TITLE-ABS-KEY (mutation) OR TITLE-ABS-KEY (allele) OR TITLE-ABS-KEY } \\
\text { (genotype))) }\end{array}$ \\
\hline
\end{tabular}

Study

ID

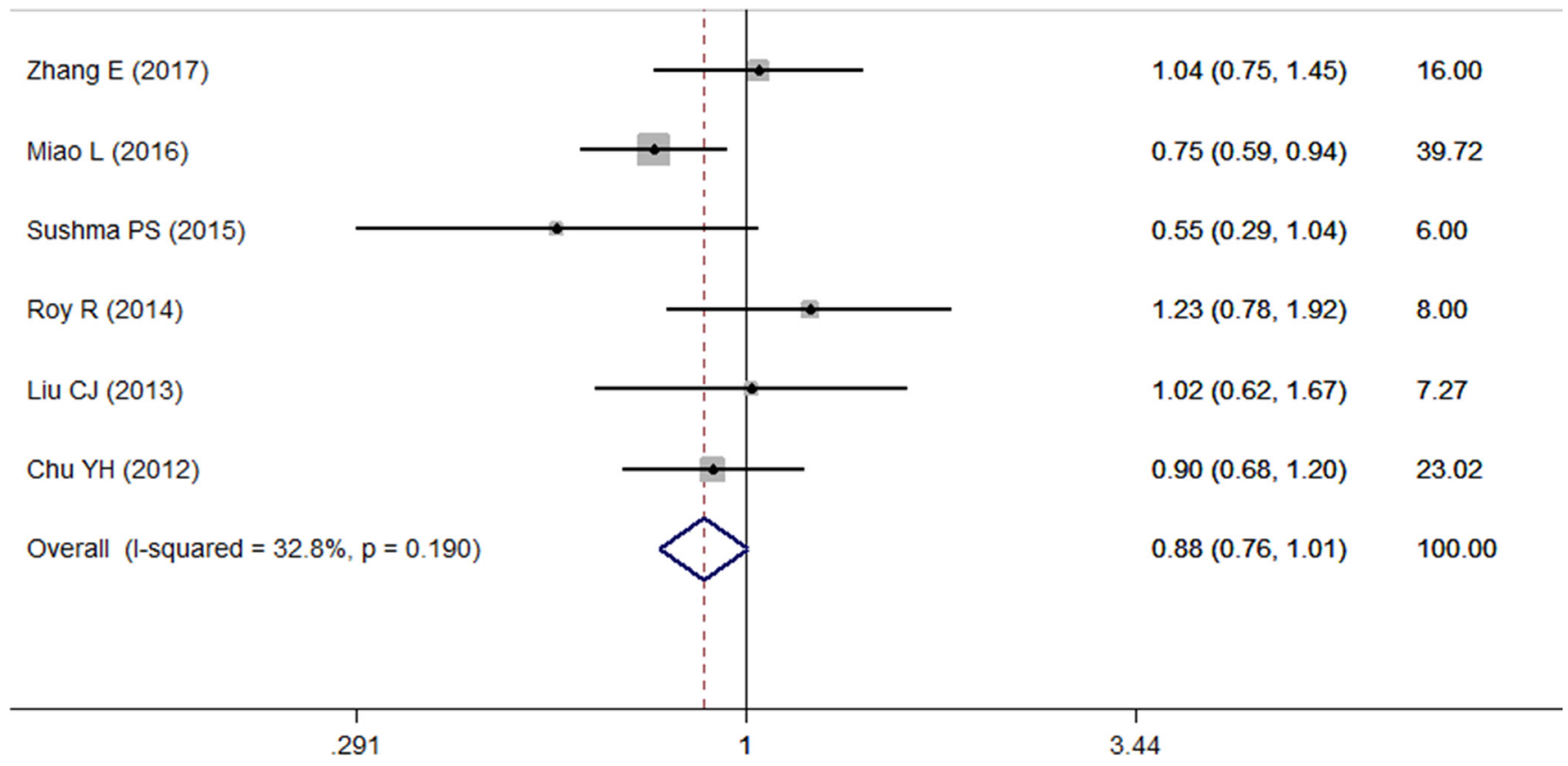

Figure 2: Forest plot of the relationship between the TT genotype of microRNA-196a2 and OSCC risk under TT vs TC+CC. 
which revealed that the upregulation of miR-196a 2 is a biomarker that can discriminate between OSCC patients and healthy controls [26]. In the present study, considering the insignificant heterogeneity, non-publication bias and statistically significant association in the sensitivity analysis of microRNA-196, it could be concluded that the TT genotype of microRNA-196a2 can reduce OSCC risk.

For microRNA-146a, the $\mathrm{G}>\mathrm{C}$ substitution within the pre-miR-146a sequence resulted in less conversion into mature miR-146a by affecting the efficiency of pri-miR146a processing. Additionally, that substitution disturbed protein binding to pre-miR-146a [27]. Incontrovertible evidence has shown that dysregulated microRNA-146a expression is related to tumorigenesis, progression and prognosis [28]. However, the role of miR-146a is complex and controversial. Increased expression of miR-146a was suggested to be a biomarker for detecting, diagnosing and tracing cancers [29]. Although a previous meta-analysis demonstrated that the $\mathrm{C}$ allele of miR-146a increased the predisposition for head and neck cancer in the Caucasian population [30], our research was more reliable because it included seven eligible studies rather than three studies. A meta-analysis of microRNAs and risk of urological cancer also showed that the miR-146a $\mathrm{G}>\mathrm{C}$ polymorphism reduced cancer risk [31]. Furthermore, a pooled analysis from a meta-analysis including 2 studies showed that the miR-146a polymorphism could reduce nasopharyngeal and OSCC risk but increase cervical cancer and skin squamous cell cancer risk [32]. Therefore, the miR-146a

\section{Study}

ID

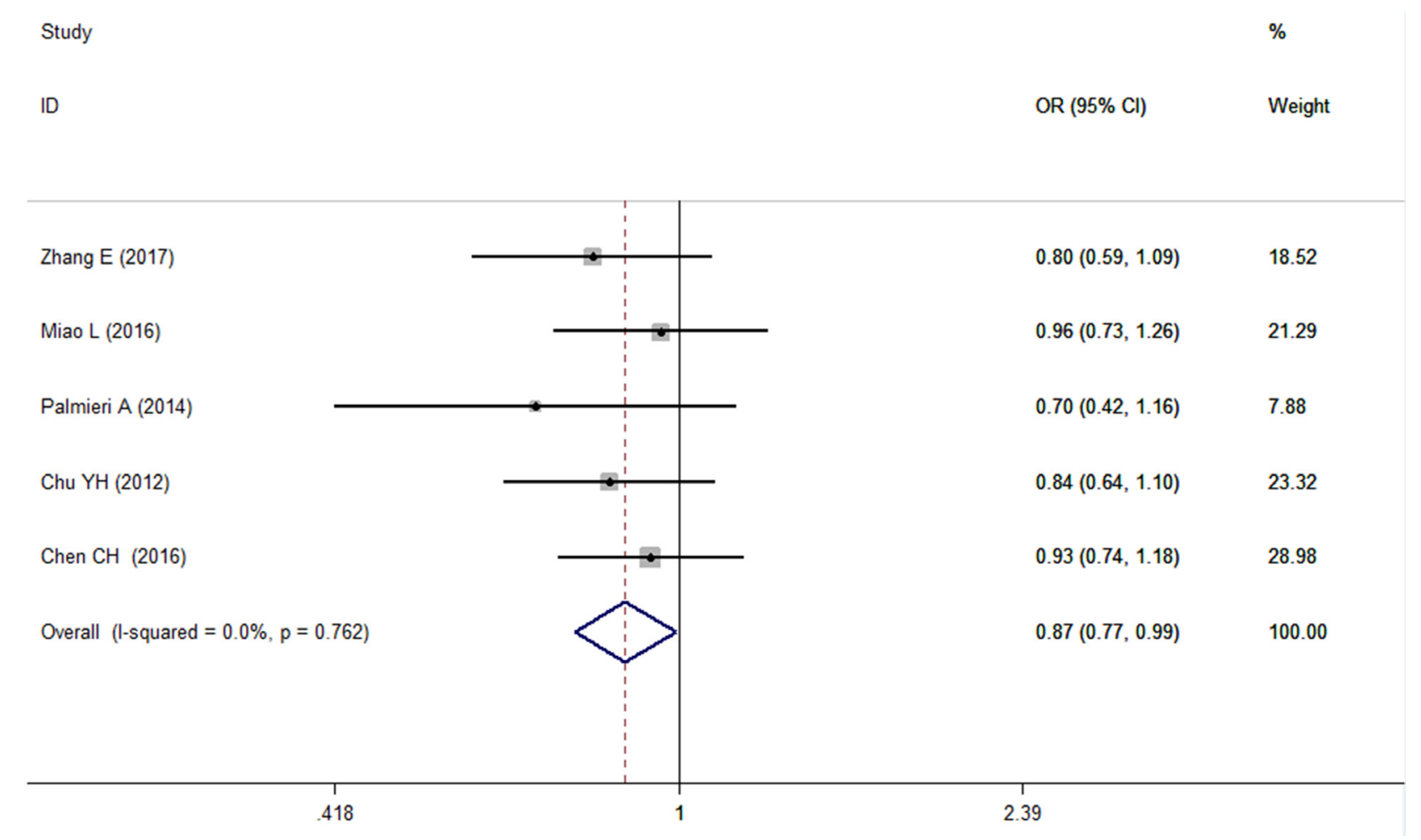

$\mathrm{G}>\mathrm{C}$ polymorphism is strongly believed to be protective against OSCC.

The miR-149 polymorphism involves a $\mathrm{C}>\mathrm{T}$ substitution. Through diverse signaling pathways, miR-149 targets Akt1, a gene that inhibits tumor cell apoptosis, thereby exerting its oncogenic potential [33]. No association between the miR-149 polymorphism and cancer risk has been identified in a meta-analysis of head and neck cancer susceptibility [30]. Likewise, in the present study, no significant association was discovered under any of the genetic models.

Located in the $3 p$ mature miRNA, the miR-499 rs3746444 A/G polymorphism interferes with miRNA binding and pre-miRNA maturation [34]. Although arm selection influences cancer progression, the miR-499 polymorphism may not affect its arm selection, so it will nonetheless reduce miR-499 expression, especially miR499-5p [19]. The miR-499a polymorphism was previously shown to be related to head-and-neck cancer and cervical squamous cell carcinoma [35]. The reason that various studies have yielded discrepancies is that they analyzed different populations or cancer locations. Furthermore, miR499 also has varying effects on cancer risk, depending on the cancer type. Our analysis demonstrated that the miR-499 polymorphism may exert protective effects against OSCC, and this finding was consistent with the reduced expression of miR-499 in OSCC tissues, as well as the negative correlation between mir-499 expression and tumor size in clinical findings.

Figure 3: Forest plot of the relationship between the CC genotype of microRNA-146a and OSCC risk under CC vs GG+CG. 
Many limitations might have influenced our findings. The most obvious limitation was the small number of included studies. Further research investigating microRNA polymorphisms and oral squamous cell cancer risk is warranted to confirm these findings. Furthermore, the poor consistency indicated by the sensitivity analysis of the recessive models of microRNA-196a2 and microRNA-146a might have influenced the statistical power of our study. Selection bias of included controls should be avoided by basing selection on the population rather than the hospital. Moreover, environmental factors, such as habits, should be balanced among studies. Other limitations of this study include a lack of subgroup analysis, disparity in OSCC location and the fact that we did not clarify non-response rates. Our meta-analysis failed to avoid these limitations due to a deficiency of data.

\section{CONCLUSIONS}

To date, studies concerned with microRNA polymorphisms and the risk of oral squamous cell cancer are insufficient and inconsistent. This review focused on four microRNA polymorphisms. The results of our metaanalysis suggest that the microRNA-196a2 and microRNA146a polymorphisms may increase OSCC risk. In contrast, the miR-499 polymorphism may exert protective effects against OSCC risk. There may be no significant association between the microRNA-149 polymorphism and OSCC risk.

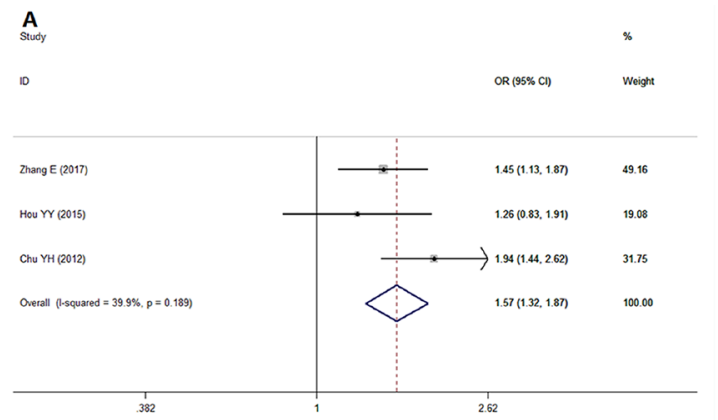

$\underset{\text { Study }}{\text { B }}$
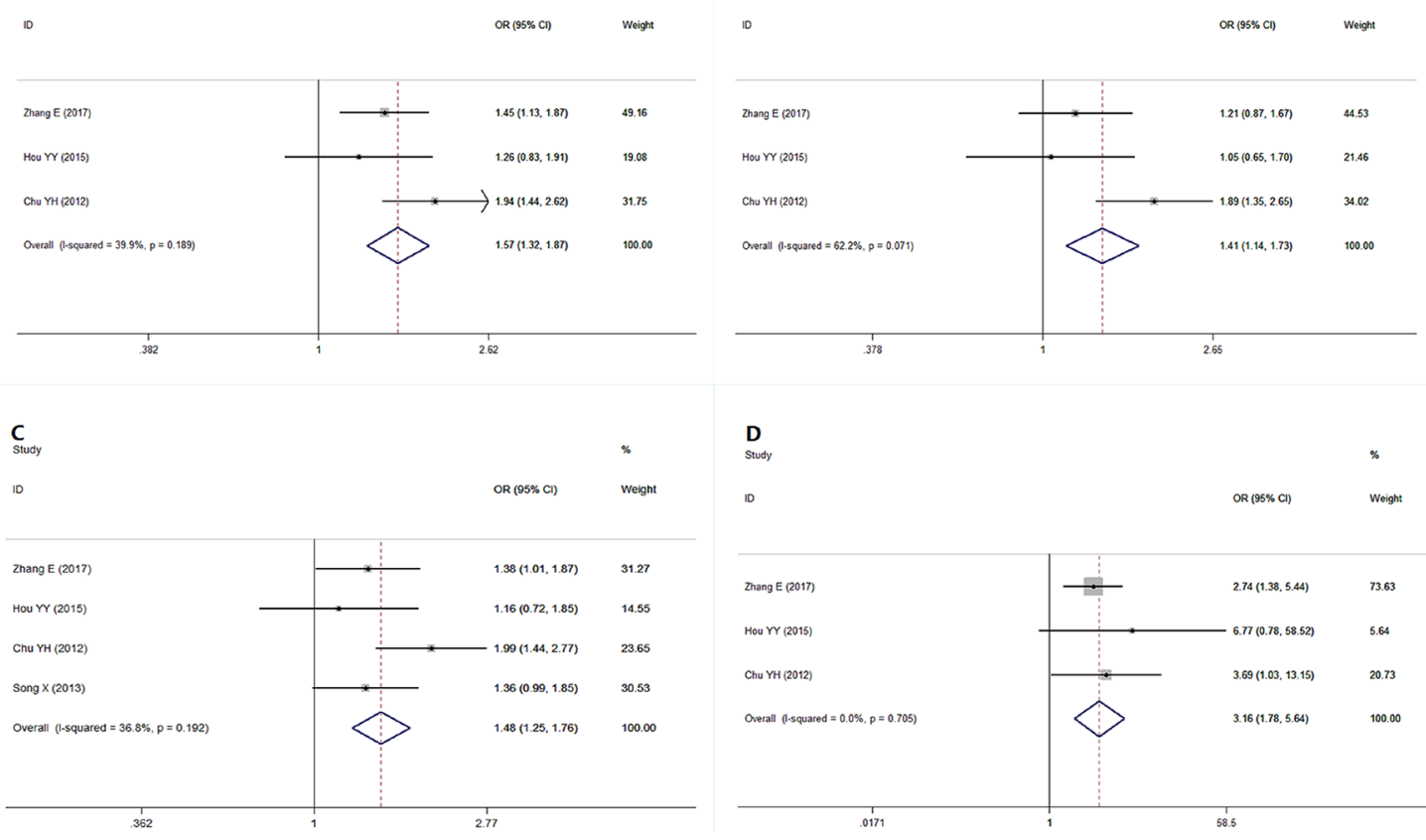

Figure 4: Forest plot showing a significant association between the microRNA-499 polymorphism and OSCC risk under various genetic models. (A) Allele model: G vs A, (B) Codominant model: GA vs AA, (C) Dominant model, GG+GA vs AA (D) Recessive model: GG vs GA+AA.
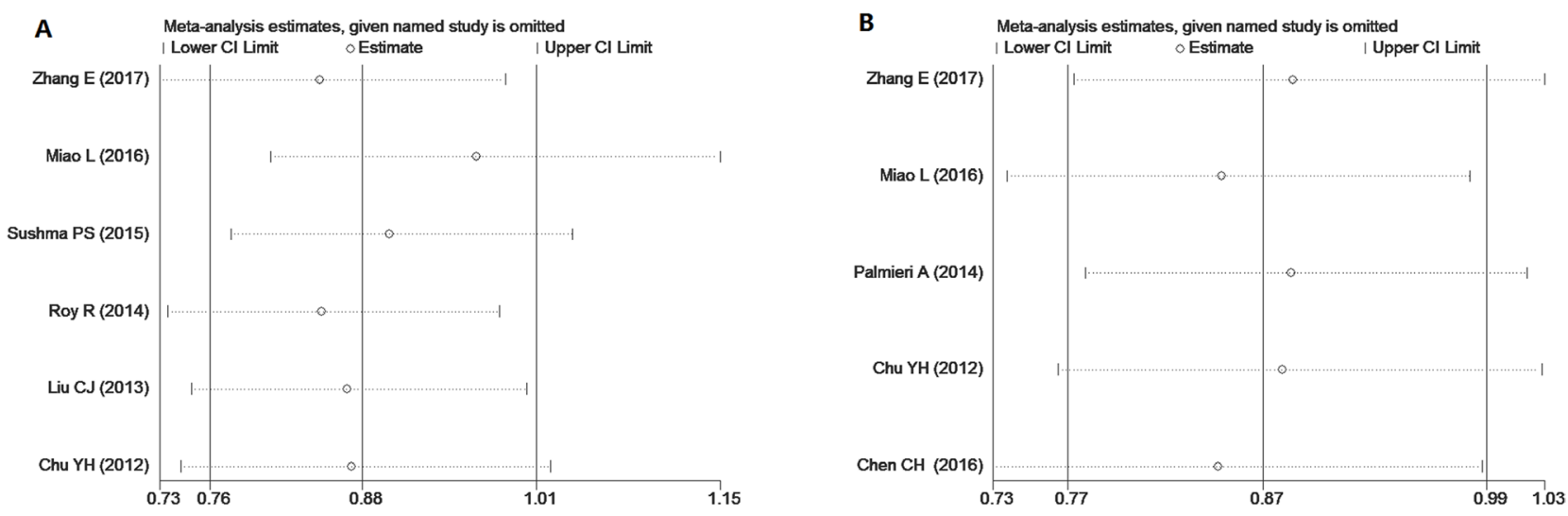

Figure 5: Sensitivity analysis conducted by sequentially eliminating one study at a time to examine the relationship between the TT genotype of miR-196a2 (A), the CC genotype of miR-146a (B) and OSCC risk. 
Due to the small number of included studies, the associations between the selected SNPs of these four microRNAs and OSCC risk are weak.

\section{MATERIALS AND METHODS}

\section{Literature sources and search strategy}

The protocol details were registered with the public registry of systematic reviews, PROSPERO (CRD42017073480). Our study was conducted by following the recommended Preferred Reporting Items for Systematic Reviews and Meta-Analyses (PRISMA) statement. A search of PubMed, Embase, Web of Science and SCOPUS was conducted through June 15, 2017, to identify all the relevant studies without language limitation. The search strategy, which employed free-text words, is shown in Table 4.

Next, titles and abstracts were read manually for preliminary analysis, in duplicate, by two reviewers. Disagreement was resolved by discussion or by referring the debate to a third reviewer. Finally, the chosen articles were subjected to the following inclusion and exclusion criteria:

\section{Selection criteria}

1. The included articles should be case-controls. 2. Patients with a definite diagnosis of oral cancer, not oral precancer, should be mentioned. 3. The included studies must contain extractable data on SNPs in pre-miR distribution in cases and controls.

\section{Exclusion criteria}

1. Articles are review articles or they describe experiments in animals. 2. Studies focus on miRNAprocessing genes or miRNA-binding site genes instead of pre-miRNA genes. 3. Studies report non-extractable data. 4. Studies in which the $P$ value for $\operatorname{HWE}\left(P_{\mathrm{HWE}}\right)$ in the control group was less than 0.05 would be eliminated from the sensitivity analysis. 5. Studies are repeated studies by the same author or team.

\section{Quality assessment and data extraction}

Each chosen study was subjected to thorough reading for data extraction, synthesis, analysis and quality assessment, following the Newcastle-Ottawa Scale (NOS) system (http://www.ohri.ca/programs/clinical_ epidemiology/oxford.asp) independently and strictly.

\section{Outcome variables and data analysis}

The minor allele frequency (MAF) was confirmed in PubMed. The outcome variables consisted of the allele and genotype frequencies of miRNA polymorphisms in cases and controls. Stata version 14.0 software was used for the data analysis. The odds ratio (OR) and 95\% confidence interval were calculated for five genetic models: the allele model, the additive model, the codominant model, the dominant model and the recessive model. The $I^{2}$ test was chosen to test for statistical heterogeneity. If $\mathrm{I}^{2} \geq$ $50 \%$, which indicates substantial heterogeneity, we used a random-effects model to summarize outcome variables. If $\mathrm{I}^{2}<50 \%$. meta-analyses were reported using a fixedeffects model. The hypothesis tested was defined as statistically significant when the $P$ value was $<0.05$.

\section{Abbreviations}

OSCC: oral squamous cell cancer; ORs: Odds ratios; miRNAs: microRNAs; UTR: untranslated region; SNPs: single nucleotide polymorphisms; HWE: Hardy-Weinberg equilibrium; HOX: homeobox; PROSPERO: public registry of systematic reviews; PRISMA: Preferred Reporting Items for Systematic Reviews and Meta-Analyses; NOS: Newcastle-Ottawa Scale; MAF: Minor allele frequency.

\section{ACKNOWLEDGMENTS}

We would like to thank "American Journal Experts" for the language editing.

\section{CONFLICTS OF INTEREST}

The authors declare no conflicts of interest.

\section{FUNDING}

None.

\section{REFERENCES}

1. Fitzmaurice C, Dicker D, Pain A, Hamavid H, MoradiLakeh M, MacIntyre MF, Allen C, Hansen G, Woodbrook R, Wolfe C, Hamadeh RR, Moore A, Werdecker A, et al, and Global Burden of Disease Cancer Collaboration. The Global Burden of Cancer 2013. JAMA Oncol. 2015; 1:50527. https://doi.org/10.1001/jamaoncol.2015.0735.

2. Shield KD, Ferlay J, Jemal A, Sankaranarayanan R, Chaturvedi AK, Bray F, Soerjomataram I. The global incidence of lip, oral cavity, and pharyngeal cancers by subsite in 2012. CA Cancer J Clin. 2017; 67:51-64. https:// doi.org/10.3322/caac.21384.

3. Chi AC, Day TA, Neville BW. Oral cavity and oropharyngeal squamous cell carcinoma--an update. CA Cancer J Clin. 2015; 65:401-21. https://doi.org/10.3322/caac.21293.

4. Maurya SS, Katiyar T, Dhawan A, Singh S, Jain SK, Pant MC, Parmar D. Gene-environment interactions in determining differences in genetic susceptibility to cancer in subsites of the head and neck. Environ Mol Mutagen. 2015; 56:313-21. https://doi.org/10.1002/em.21920. 
5. Lin CW, Chou YE, Yeh CM, Yang SF, Chuang CY, Liu YF. A functional variant at the miRNA binding site in HMGB1 gene is associated with risk of oral squamous cell carcinoma. Oncotarget. 2017; 8:34630-42. https://doi. org/10.18632/oncotarget.16120.

6. Kulkarni V, Uttamani JR, Naqvi AR, Nares S. microRNAs: emerging players in oral cancers and inflammatory disorders. Tumour Biol. 2017; 39:1010428317698379. https://doi.org/10.1177/1010428317698379.

7. Bartel DP. MicroRNAs: genomics, biogenesis, mechanism, and function. Cell. 2004; 116:281-97.

8. Rosenfeld N, Aharonov R, Meiri E, Rosenwald S, Spector Y, Zepeniuk M, Benjamin H, Shabes N, Tabak S, Levy A, Lebanony D, Goren Y, Silberschein E, et al. MicroRNAs accurately identify cancer tissue origin. Nat Biotechnol. 2008; 26:462-9. https://doi.org/10.1038/nbt1392.

9. Zhang E, Xu Z, Duan W, Huang S, Lu L. Association between polymorphisms in pre-miRNA genes and risk of oral squamous cell cancer in a Chinese population. PLoS One. 2017; 12:e0176044. https://doi.org/10.1371/journal. pone. 0176044 .

10. Chu YH, Tzeng SL, Lin CW, Chien MH, Chen MK, Yang SF. Impacts of microRNA gene polymorphisms on the susceptibility of environmental factors leading to carcinogenesis in oral cancer. PLoS One. 2012; 7:e39777. https://doi.org/10.1371/journal.pone.0039777.

11. Liu CJ, Tsai MM, Tu HF, Lui MT, Cheng HW, Lin SC. miR196a overexpression and miR-196a2 gene polymorphism are prognostic predictors of oral carcinomas. Ann Surg Oncol. 2013 (Suppl 3); 20:S406-14. https://doi. org/10.1245/s10434-012-2618-6.

12. Miao L, Wang L, Zhu L, Du J, Zhu X, Niu Y, Wang R, $\mathrm{Hu}$ Z, Chen N, Shen H, Ma H. Association of microRNA polymorphisms with the risk of head and neck squamous cell carcinoma in a Chinese population: a case-control study. Chin J Cancer. 2016; 35:77. https://doi.org/10.1186/ s40880-016-0136-9.

13. Roy R, De Sarkar N, Ghose S, Paul RR, Pal M, Bhattacharya C, Chowdhury SK, Ghosh S, Roy B. Genetic variations at microRNA and processing genes and risk of oral cancer. Tumour Biol. 2014; 35:3409-14. https://doi. org/10.1007/s13277-013-1450-3.

14. Song X, Sturgis EM, Liu J, Jin L, Wang Z, Zhang C, Wei Q, Li G. MicroRNA variants increase the risk of HPVassociated squamous cell carcinoma of the oropharynx in never smokers. PLoS One. 2013; 8:e56622. https://doi. org/10.1371/journal.pone.0056622.

15. Sushma PS, Jamil K, Kumar PU, Satyanarayana U, Ramakrishna M, Triveni B. Genetic Variation in MicroRNAs and Risk of Oral Squamous Cell Carcinoma in South Indian Population. Asian Pac J Cancer Prev. 2015; 16:7589-94. https://doi.org/10.7314/apjcp.2015.16.17.7589.

16. Christensen BC, Avissar-Whiting M, Ouellet LG, Butler RA, Nelson HH, McClean MD, Marsit CJ, Kelsey KT.
Mature microRNA sequence polymorphism in MIR196A2 is associated with risk and prognosis of head and neck cancer. Clin Cancer Res. 2010; 16:3713-20. https://doi. org/10.1158/1078-0432.CCR-10-0657.

17. Palmieri A, Carinci F, Martinelli M, Pezzetti F, Girardi A, Cura F, Rubini C, Scapoli L. Role of the MIR146A polymorphism in the origin and progression of oral squamous cell carcinoma. Eur J Oral Sci. 2014; 122:198201. https://doi.org/10.1111/eos.12121.

18. Chen HC, Tseng YK, Chi CC, Chen YH, Yang CM, Huang SJ, Lee YC, Liou HH, Tsai KW, Ger LP. Genetic variants in microRNA-146a $(\mathrm{C}>\mathrm{G})$ and microRNA-1269b $(\mathrm{G}>\mathrm{C})$ are associated with the decreased risk of oral premalignant lesions, oral cancer, and pharyngeal cancer. Arch Oral Biol. 2016; 72:21-32. https://doi.org/10.1016/j. archoralbio.2016.08.010.

19. Hou YY, Lee JH, Chen HC, Yang CM, Huang SJ, Liou HH, Chi CC, Tsai KW, Ger LP. The association between miR-499a polymorphism and oral squamous cell carcinoma progression. Oral Dis. 2015; 21:195-206. https://doi. org/10.1111/odi.12241.

20. Karatas OF, Oner M, Abay A, Diyapoglu A. MicroRNAs in human tongue squamous cell carcinoma: from pathogenesis to therapeutic implications. Oral Oncol. 2017; 67:124-30. https://doi.org/10.1016/j.oraloncology.2017.02.015.

21. Troiano G, Boldrup L, Ardito F, Gu X, Lo Muzio L, Nylander K. Circulating miRNAs from blood, plasma or serum as promising clinical biomarkers in oral squamous cell carcinoma: A systematic review of current findings. Oral Oncol. 2016; 63:30-7. https://doi.org/10.1016/j. oraloncology.2016.11.001.

22. Chen C, Zhang Y, Zhang L, Weakley SM, Yao Q. MicroRNA-196: critical roles and clinical applications in development and cancer. J Cell Mol Med. 2011; 15:14-23. https://doi.org/10.1111/j.1582-4934.2010.01219.x.

23. Yekta S, Shih IH, Bartel DP. MicroRNA-directed cleavage of HOXB8 mRNA. Science. 2004; 304:594-6. https://doi. org/10.1126/science.1097434.

24. Mueller DW, Bosserhoff AK. MicroRNA miR-196a controls melanoma-associated genes by regulating HOX-C8 expression. Int J Cancer. 2011; 129:1064-74. https://doi. org/10.1002/ijc.25768.

25. Hoffman AE, Zheng T, Yi C, Leaderer D, Weidhaas J, Slack F, Zhang Y, Paranjape T, Zhu Y. microRNA miR-196a-2 and breast cancer: a genetic and epigenetic association study and functional analysis. Cancer Res. 2009; 69:5970-7. https://doi.org/10.1158/0008-5472.CAN-09-0236.

26. Tian X, Chen Z, Shi S, Wang X, Wang W, Li N, Wang J. Clinical Diagnostic Implications of Body Fluid MiRNA in Oral Squamous Cell Carcinoma: A Meta-Analysis. Medicine (Baltimore). 2015; 94:e1324. https://doi. org/10.1097/MD.0000000000001324.

27. Jazdzewski K, Murray EL, Franssila K, Jarzab B, Schoenberg DR, de la Chapelle A. Common SNP in 
pre-miR-146a decreases mature miR expression and predisposes to papillary thyroid carcinoma. Proc Natl Acad Sci USA. 2008; 105:7269-74. https://doi.org/10.1073/ pnas.0802682105.

28. Wang C, Guan S, Liu F, Chen X, Han L, Wang D, Nesa EU, Wang X, Bao C, Wang N, Cheng Y. Prognostic and diagnostic potential of miR-146a in oesophageal squamous cell carcinoma. Br J Cancer. 2016; 114:290-7. https://doi. org/10.1038/bjc.2015.463.

29. Sasaki H, Yoshiike M, Nozawa S, Usuba W, Katsuoka Y, Aida K, Kitajima K, Kudo H, Hoshikawa M, Yoshioka Y, Kosaka N, Ochiya T, Chikaraishi T. Expression Level of Urinary MicroRNA-146a-5p Is Increased in Patients With Bladder Cancer and Decreased in Those After Transurethral Resection. Clin Genitourin Cancer. 2016; 14:e493-e9. https://doi.org/10.1016/j.clgc.2016.04.002.

30. Niu YM, Du XY, Lu MY, Xu QL, Luo J, Shen M. Significant association between functional microRNA polymorphisms and head and neck cancer susceptibility: a comprehensive meta-analysis. Sci Rep. 2015; 5:12972. https://doi.org/10.1038/srep12972.

31. Wang YH, Hu HN, Weng H, Chen H, Luo CL, Ji J, Yin CQ, Yuan CH, Wang FB. Association between Polymorphisms in MicroRNAs and Risk of Urological Cancer: A MetaAnalysis Based on 17,019 Subjects. Front Physiol. 2017; 8:325. https://doi.org/10.3389/fphys.2017.00325.
32. Zhang X, He R, Ren F, Tang R, Chen G. Association of miR-146a rs2910164 polymorphism with squamous cell carcinoma risk: a meta-analysis. J BUON. 2015; 20:829-41.

33. Si L, Xu L, Yin L, Qi Y, Han X, Xu Y, Zhao Y, Liu K, Peng J. Potent effects of dioscin against pancreatic cancer via miR-149-3P-mediated inhibition of the Akt1 signalling pathway. Br J Pharmacol. 2017; 174:553-68. https://doi. org/10.1111/bph.13718.

34. Landgraf P, Rusu M, Sheridan R, Sewer A, Iovino N, Aravin A, Pfeffer S, Rice A, Kamphorst AO, Landthaler M, Lin C, Socci ND, Hermida L, et al. A mammalian microRNA expression atlas based on small RNA library sequencing. Cell. 2007; 129:1401-14. https://doi.org/10.1016/j. cell.2007.04.040.

35. Zhou B, Wang K, Wang Y, Xi M, Zhang Z, Song Y, Zhang L. Common genetic polymorphisms in pre-microRNAs and risk of cervical squamous cell carcinoma. Mol Carcinog. 2011; 50:499-505. https://doi.org/10.1002/mc.20740. 